\title{
From memory to jewellery - perspectives on memory in Italian and Danish jewellery design
}

This paper examines the relationship between design and memory in Italian and Danish jewellery design. In Italy, there is a long tradition of working consciously with cultural memory, which adds layers of memory to design objects, mainly through inspiration from art, architecture, literature, philosophy and sociology. The memory dimension also plays a role in Danish jewellery design as a part of Danish cultural heritage. Here, the sources of inspiration mainly come from the symbols of nature.

The paper draws especially on hermeneutical reflections around memory and on theoretical perspectives from material culture, practical works and interviews with prominent designers (Alessandro Mendini, Stefano Marchetti, Kim Buck) and Alberto Alessi. The distinction between Italian and Danish design is discussed through relevant examples of design from both countries. Designing objects charged with memory is a slow process and, in continuation of this, it takes time to acknowledge the underlying layers. There is a lack of research in the use of memory within contemporary jewellery design, especially seen from the perspective of the designer. The aim of this paper is to contribute to this field of research.

keywords jewellery, design, memory, Italy, Denmark

\section{Introduction}

Design represents a central form of cultural communication. Today, practical and functional needs are often put aside in favor of other values. This is for example the case with memory design produced by the Italian design firm Alessi. When designers from Alessi create their products, they are usually inspired by cultural forms, often specifically by the concept of memory in art, architecture, literature, philosophy, sociology and psychology. The concept of memory is valued because it adds a critical dimension to design objects, enabling the objects to make an identity-forming impact. (Alessi, 2008) In Italy, there has been a long tradition in design and architecture schools of focusing on the humanities, making cultural memory an essential part of the education as seen at the Padua School and the Polytechnic University of Milan.

Designing objects charged with layers of memory is a slow process and, in continuation of this, it takes time to acknowledge the underlying layers. The notion of memory design is related to an involvement of all senses in the memory process. Through materials, forms, techniques, content, and themes the designers draw analogies between past and present, which paves the way for future thinking.

Traditionally, Danish design has focused on form and function with frequent references to the forms of nature. The question is in what way memory plays a role in Danish design. 
In Cultural Memory and Early Civilization Jan Assmann points out that memory concerns how we are reflected by objects. He describes how objects become identity-forming as they communicate who we are, our past, our ancestors. (Assmann, 2011, p. 6)

Memory in jewellery design concerns the creation of 'slow jewellery' as opposed to 'fast fashion'. In this way, it has to do with a material and thus mental sustainability, because the objects become precious in the sense of forming your identity so that you keep them and do not throw them away.

There is a lack of research in the use of memory within contemporary jewellery design. The memory dimension has been viewed as primarily an important private function of jewellery. (Ahde-Deal, 2013) However, memory is also public and thus collective and can be imbedded in objects from the beginning of the design process from a corporate perspective (Alessi), which in the end may affect the personal memories of the personal user. This paper primarily focuses on the memory dimension in jewellery design from the designer's perspective drawing on analyses of first Italian and subsequently Danish jewellery design examples and on interviews' with the involved designers.

\section{In search of lost time}

The Italian designer Alessandro Mendini became design consultant for Alessi in 1979. From then on, he was the leading figure in promoting skill and professionalism in matter of planning art and design as a bridge to the outside world. He arranged research workshops that aimed to develop both research and an intellectually stimulating environment and to invent new products for Alessi. He began to work deliberately with memory in these workshops together with students and researchers from fields such as psychology, sociology and philosophy. Alberto Alessi points out that memory in the eighties was a key issue to Alessi designers. It was in experimental workshops such as "Family Follows Fiction" that a lot of unforeseen things happened. Here, children's drawings of rabbits where used in order to change the way we normally see classical egg cups where form follows function. Now, egg cups became an expression of children's love for silly forms and colours. ${ }^{2}$ (Alessi, 2008)

Mendini began to work consciously with the theme of memory in 1978, where he made a tribute to Marcel Proust's novel "In Search of Lost Time". He explains that

"Proust's novel concerns infinity as it always will be a part of my luggage. I decided to create textile for Proust. I went to Paris and visited the place where he lived. I realized that there was a connection between Proust and the pointillist painter Poul Signac (1863-1935). The rooms where Proust lived were very baroque. So I began by making pointillist textile, and I later united this with a baroque armchair. The armchair should be hand painted. The chair was not a design, an object, a picture or a sculpture, but an ambiguous object. The small

\footnotetext{
The use of memory in the design process is difficult to quantify, especially because the storytelling surrounding the objects awakens memories of different kinds (happy, unhappy, etc.). This is the reason why a qualitative method approach is used. These interviews are based on a combination of phenomenological and hermeneutical questioning.

${ }^{2}$ In Alessi's case, it is a sort of "happy memory", borrowing Paul Ricoeur's term, introduced in his book Memory, History, Forgetting from 2000. He stresses that happy remembering represents a wish of being faithful to the past.
} 
spots characterize my work because here the quality of the whole is dependent of the parts being good. You can also interpret the city in that way. If every person (house) is good then the city becomes a good place to live. So I continued with this pointillist method on both small and large objects, right from a Proust cork screw to a Proust watch. To me, Pointillism created mosaics. Mosaics can cover the entire world. Memory becomes fragmented in spots. It expresses the atmosphere and the energy between things in the world". (Mendini, 2013)

Watches have become jewellery today. Mendini repeats the Proust spots in order to create a connection between past and present. His watch lacks numbers that indicate that time passes, stressing that mechanical time is unnecessary when it comes to memories. Through memories past, present and future are interwoven and chronology disappears and thus, the taste of a madeleine cake mixed with linden tea may evoke involuntary memories of bygone times. (Proust,1999, p. 55) In that way memory design can be a critical reminder of that we sometimes have to stop mechanical time.

\section{Filtering memory through a mocha pot}

The Italian designer Stefano Marchetti states that it is important that the new generation of designers filter memory like a mocha pot. Some should be saved and some should be forgotten. He teaches his students to deconstruct the mocha pot by recreating small pieces, where the material and the shapes are preserved but also transformed into a contemporary look. Marchetti questions what relationship we have with cultural products today. We use them for generations without knowing the original meaning behind them anymore, and then we forget them. (Marchetti, 2010)

Hans-Georg Gadamer theorizes that memory concerns the notion that some things have to be remembered and other things have to be forgotten. Forgetting is important for our ability to memorize, because forgetting makes it possible to see everything with fresh eyes. Forgetting is in that way about discovering something new (innovation), but forgetting cannot be on its own without our memory. The goal is for the known (memory) to fuse with forgetting (the newly discovered) into a multifarious whole.(Gadamer,2004,p. 20)

This is exactly what Marchetti does with his bracelet, where he creates fragments of the past taking inspiration from Etruscan mosaics. Instead of merely copying idioms of the past, he filters the past and puts it into a present context. The bracelet has several cracks as if it cannot keep together, which is in opposition to Etruscan time where the outer shape was unbroken. Memory is thus vulnerable and will disappear if untold. 
theme 2

memory

Figure 2.

Stefano Marchetti: Bracelet (1993), gold, red gold, silver and copper.
Figure 3.

Kim Buck: "Loves me, loves me not" (2007), brooch; silver, gold and enamel. strand 1

design histories: tradition, transgression and transformations

Marchetti wondered why mosaics were absent in the Italian jewellery tradition in contrast to the architectural tradition. Consequently, he decided to try to develop a new technique and explore in what way he would be able to make mosaics today, creating a fusion between past and present with inspiration from e.g. pointillism. In his work and teaching, he attempts to create a modern memory based on the fusion of memories from the past and present.To Marchetti, it is impossible to re-establish the original historical meaning behind design. This is why history to him becomes picked fruit that he must reconstruct.

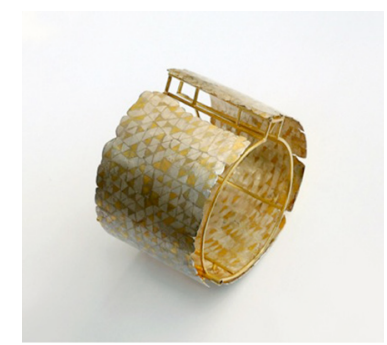

\section{The Daisy flower - a transformation of Danish cultural memory}

Denmark has its own popular jewellery cliché, the Daisy brooch. It was originally designed by A. Michelsen in honor of the birth of Queen Margrethe II in 1940. The brooch was shaped as a daisy and made of enamel and silver. It supported a strong national feeling in the time during and after the Second World War, signaling a positive hope for a new and better future. The golden and white colors of the daisy signal an opposition to occupation and blackout curtains that hide and oppress joy and mark fear.

Michael von Essen, former curator at the Georg Jensen Museum in Copenhagen, has explained that the Daisy was launched by Georg Jensen without deliberately using the Queen's history. However, Danes are also aware of the fact that the Queen wears Daisy jewellery and thus, the Daisy is associated with her. Today, the daisy flower in the user's mind is more associated with the marguerite (daisy) routes in Denmark, where you can explore the Danish nature. (Essen, 2009) Hence, many Danes do not wear this flower any longer as a cultural symbol but rather because it presents a memory of Denmark as a beautiful country surrounded by nature.

The Daisy is a stylized version of the Danish nature. In that way the apparent and initially proposed dichotomy of culture (Italy) versus nature (Denmark) can be questioned because the two concepts are fused in the design process. This fusion constitutes a translation and transformation of the Danish nature in the mind of the designer. The stylized Daisy underlines the fact that nature has been transformed. In reality, the Danish nature is almost entirely cultivated, mainly due to agriculture.

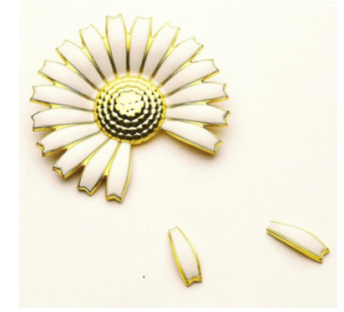


The Danish designer Kim Buck has paraphrased the Daisy, questioning its historical importance. (Buck, 2009) He experiments with the Daisy by making everything from a thick Daisy block to a silhouette of a Daisy. In that way, he plays with the importance of the Daisy in our memory: from a strong one to a fragile one. It is no longer a perfect form, it is a deformed version. Buck suggests that a lot of people do not know the story behind the Daisy as a resistance symbol. It has become a part of the Danish cultural heritage but the original story has changed. Today, it is rather a story about our love life, referring to the 'loves me, loves me not' game. Michelsen transformed the Daisy flower as a symbol of Danish cultural memory, and later this transformation is drawn in the direction of more shared cultural memory by problematizing our love lives in the 'loves me, loves me not' game in Buck's version, as this game can be understood by different cultures.

\section{Conclusion}

Memory is the past in the present. It is nurtured and passed on, shaped and added to, by each generation. Memory is about making the past relevant to the present, but it is also about creating a memory filter so that some things can be chosen and other things forgotten.

Memory design appeals to reflection and has a critical potential, which the chosen examples show. This critical potential is first activated if the company is aware of the potential of memory designs. This may be the reason why designers such as Kim Buck have been reluctant to be fully involved in the Danish company Georg Jensen, because Georg Jensen has not established creative platforms, such as research labs, as seen with Alessi. Consequently, the involvement of memory in design may be more random and unconscious when not implemented in the company's strategy. The story behind the Daisy flower is laden with memory. If companies look more at people as individuals and not just as a mass of users the importance of this story would gain weight. In the end it could change the way we look at and perceive design.

Mendini suggests that the second life of objects is important. The objects first gain qualities of humanity and compassion with time by the people who use them. Many objects today are rapidly devalued. They are intended to break and change quickly. It is a fast culture as opposed to a slow culture. You need a slow culture, which is what memory is about. (Mendini, 2013) The jewellery examples chosen for this paper get a second life through the conversations about and around them. Memory in jewellery design concerns the creation of "slow jewellery" in opposition to "fast fashion". (Hines \& Bruce, 2001) Slow jewelries are precious as they can form and transform our identity. They possess the potential to last and thus to become a part of our cultural memory.

\section{References}

Ahde-Deal, P., 2013. Women and Jewelry - A Social Approach to Wearing and Possessing Jewelry. Doctoral Dissertation. Helsinki: Alto Art Books.

Alessi, A., 2008. Author's conversation [Interview] (29 February 2008).

Assmann, J., 2011. Cultural Memory and Early Civilization. Writing, Remembrance and Political Imagination. Cambridge: Cambridge University Press.

Buck, K., 2009. Author's conversation [Interview] (25 May 2009).

Dybbøl, M. \& Vinther, S. U., 2009. Hofjuveler A. Michelsen. Fra stilkopi til arkitektsølv.

Malene Dybbøl \& Sabrina Ulrich Vinther ed. Copenhagen: Nyt Nordisk Forlag Arnold Busck.

Essen, M. v., 2009. Author's conversation [Interview] (17 November 2009). 
theme 2

memory strand 1

design histories: tradition, transgression and transformations

Gadamer, H.-G., 2004. Truth and Method. 1 ed. Aarhus: Systime Academic. Hines, T. \& Bruce, M., 2001. Fashion marketing. Contemporary issues. Oxford: Butterworth-Heinemann.

Marchetti, S., 2010. Author's conversation [Interview] (2 September 2010).

Mendini, A., 2013. Author's conversation [Interview] (19 September 2013).

Proust, M., 1999. In Search of Lost Time. Swann's Way. Copenhagen: Rosinante Forlag A/S. 